\title{
Jefferson
}

Thomas Jefferson University

$\overline{\text { HOME OF SIDNEY KIMMEL MEDICAL COLLEGE }}$

Jefferson Journal of Psychiatry

Volume 9 | Issue 1

Article 9

January 1991

\section{Occupational Chemical Exposures and Psychiatric Disorders}

Mark L. Dembert, M.D., M.P.H.

U.S. Naval Hospital, Portsmouth, Virginia

Follow this and additional works at: https://jdc.jefferson.edu/jeffjpsychiatry

Part of the Psychiatry Commons

Let us know how access to this document benefits you

\section{Recommended Citation}

Dembert, M.D., M.P.H., Mark L. (1991) "Occupational Chemical Exposures and Psychiatric Disorders," Jefferson Journal of Psychiatry. Vol. 9 : Iss. 1 , Article 9.

DOI: https://doi.org/10.29046/JJP.009.1.007

Available at: https://jdc.jefferson.edu/jeffjpsychiatry/vol9/iss1/9

This Article is brought to you for free and open access by the Jefferson Digital Commons. The Jefferson Digital Commons is a service of Thomas Jefferson University's Center for Teaching and Learning (CTL). The Commons is a showcase for Jefferson books and journals, peer-reviewed scholarly publications, unique historical collections from the University archives, and teaching tools. The Jefferson Digital Commons allows researchers and interested readers anywhere in the world to learn about and keep up to date with Jefferson scholarship. This article has been accepted for inclusion in Jefferson Journal of Psychiatry by an authorized administrator of the Jefferson Digital Commons. For more information, please contact: JeffersonDigitalCommons@jefferson.edu. 


\title{
Occupational Chemical Exposures and Psychiatric Disorders
}

\author{
Mark L. Dembert, M.D., M.P.H.
}

\begin{abstract}
Occupational exposure to metals, solvents, or pesticides can produce disorders of behavior, thought, or mood which can easily be misdiagnosed as "functional." Accurate diagnosis obtained with a relevant clinical history, psychiatric interview, physical examination, and indicated laboratory tests will enable the delivery of necessary medical treatment and concurrently prevent repeat exposure to a hazardous work environment. Published references and organizational sources in occupational medicine and industrial hygiene can be utilized by psychiatrists for determination of the differential diagnosis and confirmation of an occupational exposure; in addition, these references can aid in assessing the need for an environmental health hazard survey at the worksite.
\end{abstract}

Upwards of eight million persons in the U.S. are estimated to be exposed to any of the approximately 850 workplace chemicals which are felt to be possibly neurotoxic (1). However, the proportion of workers with occupational chemical exposures who have secondary neuropsychiatric manifestations and are appropriately diagnosed and treated is unknown.

A misdiagnosis of a primary (nonorganic) psychiatric disorder in a worker from any industrial setting, when there is actually an occupational exposure and etiology involved, can result not only in the patient getting the wrong immediate treatment but also in the eventual return of the patient to the implicated worksite with continued exposure. This can happen among workers at large industries with medical departments. This can also occur in small industries where both managers and workers remain unaware of chemical and other environmental hazards, personal protective equipment, medical monitoring for exposed workers, and industrial hygiene surveillance of specific hazards. Such workers in these latter settings, perhaps multiply exposed, are at risk for having true occupationally-related psychiatric and medical illnesses "misdiagnosed" at an outside general medical clinic or private office where physicians and patients alike do not ask questions regarding industrial exposures.

Correspondence address: Department of Psychiatry Naval Hospital Naval Training Center Great Lakes, IL 60088.

Acknowledgement: The views expressed in this article are solely those of the author and do not reflect the official policy or position of the Department of the Navy, Department of Defense, or the U.S. Government. The assistance of A. Blair Smith, M.D. and Jane Pellegrino in the development of this article is appreciated. 
The military conducts active and comprehensive industrial hygiene and occupational surveillance programs. Three recent cases known to the author-cases involving military personnel who presented with psychiatric symptoms subsequently diagnosed as caused by occupational chemical exposures-are presented as examples:

Case 1. Mr. A, a 36 year old sailor with sixteen years of outstanding service in the naval aviation repair field, was admitted to a military hospital in an acute confusional state. He had recently worked for several hours on a helicopter engine and was exposed to heavy exhaust fumes as well as to aviation jet fuel, without wearing required respiratory protection. He displayed bizarre behavior, disorganized thinking, psychomotor hyperactivity, pressured rambling speech with reported flight of ideas, impaired orientation, and confusion for the ensuing two days before hospitalization. All signs and symptoms resolved rapidly without sequelae. Further history revealed two previous brief episodes of similar self-limited confusional states temporally related to significant unprotected exposure to aviation gasolines and exhaust fumes. He had returned to full duty both times. A job change was advised which precluded the above occupational exposures.

Case 2. Mr. B, a 21 year old sailor with three years of general naval service, was admitted to a military hospital in a mute and catatonic state. He had mixed and then applied paints for several hours in a poorly ventilated shipboard space without wearing required respiratory protection. He was found later that evening in his berth, with normal vital signs but curled up in a fetal position and unresponsive to direct commands despite appearing awake. Socialization and cognitive and motor functions rapidly returned to normal during hospitalization. A previous psychiatric hospitalization in 1986 documented an avoidant personality disorder and returned him to full duty. Recent psychosocial stressors at work prompted escalation of avoidant traits and impaired work performance. A diagnosis of Organic Mental Disorder Not Otherwise Specified (NOS) (2), secondary to significant acute and mixed solvent exposure, was concurrently documented.

Case 3. Mr. C, a 33 year old sailor with fifteen years of exemplary naval submarine service, was admitted to a military hospital because of a two month history of incapacitating multiple somatic complaints with less than expected physical and laboratory findings on multispecialty workups. Ataxia, moderate resting/intention tremor especially of the hands, was observed. He described concurrent timidity, social anxiety, irritability, depressed and anxious mood without specific provocative psychosocial stressors, and feelings of hopeless without suicidal ideation. There was no substance abuse history. A urine heavy metal screen revealed a significantly elevated mercury level. Occupational medicine and industrial hygiene consultants performed a site visit of his apartment and found significant airborne mercury levels. Further investigation found that his upstairs neighbor had shoddily repaired a standard barometer as part of a side business and then stored it in a closet. The mercury in the barometer leaked out through worn floorboards and into the ceiling of the patient's apartment. It was inhaled by the patient over several weeks prior to the onset of his symptoms. The clinical picture was consistent with classical inorganic mercury 
poisoning (3). He was treated with penicillamine chelation therapy and later returned to duty.

Especially for the psychiatrist practicing in an industrial area, a working knowledge of basic occupational medicine principles, an intuitive consideration of occupational chemical exposure as part of the psychiatric differential diagnosis, and knowledge of how to proceed to confirm the diagnosis utilizing specific reference sources, are important. The goal of this article is to provide such information in the framework of evaluation, disorder and exposure, and reference sources.

\section{PATIENT EVALUATION FROM A COMBINED PSYCHIATRY-OCGUPATIONAL MEDICINE PERSPECTIVE}

\section{Neuropsychiatric Examination}

A comprehensive psychiatric and neurological examination is essential. Many chemical exposures adversely affect both the central and peripheral nervous systems. A general approach to classifying the examination and findings would be: general intellectual impairments; motor impairments; sensory impairments; memory and learning impairments; visuospatial impairments; and mood, thought, and/or behavior disorders. A multiaxial diagnostic formulation using Diagnostic and Statistical Manual of Mental Disorders, Third Edition, Revised (DSM-III-R) (2) criteria can then be made. However, demographic information, including work history, may indicate the need for a more extensive occupational history.

\section{Occupational Medicine History}

The occupational history as part of the medical examination of any patient has assumed greater importance in clinical practice in recent years-particularly with the growing medicolegal concerns about health hazards in the work place. Preplacement (pre-employment) and periodic examinations are routinely performed in numerous industries to establish baseline health status and to detect subtle or gross health changes related to exposure to a particular chemical or to other forms of manifest energy, e.g., vibration, irradiation, sound waves. Essential information contained in the occupational medicine history includes:

1. Demographic data: race, sex, age, nationality.

2. Work history: chronological summary of current and past full-time, parttime, and summer jobs; descriptions of hours and duties; particular exposures by specific chemical or by general nature, e.g., dusts, fumes, liquids, vapors, gases, pressure, vibration, temperature extremes, chemicals, ionizing or nonionizing radiation, biological agents; when and what types of protective equipment have been worn.

3. Military (peace and war-time) assignments and possible chemical exposures.

4. Symptoms or disorders related to work: how are the symptoms and signs 
temporally related to chemical exposures, days of week, number of hours, whether during or after work.

5. Hobbies (avocations) and their exposures.

6. Allergies to environment, foods, or medications.

7. Current medications.

8. Past psychiatric history.

9. Past medical history, injuries, operations.

10. Sleep patterns.

11. Nutritional status.

12. Use of tobacco products, alcohol beverages, caffeine-containing beverages.

13. Past geographic history, e.g., residences in communities or areas where concurrent sources of exposure existed, e.g., toxic waste disposal areas, mines, heavy chemical industries.

14. Family occupational history, e.g., spouse, children, parents, or roommates.

\section{Defining Exposure}

Many reports use the terms "acute" or "chronic" when relating an exposure to a disorder. They will be used in this article as reflective of cited literature. However, these terms are not well-defined in the literature. What is most important is to consider a possible chemical exposure as a proximate cause. Duration of exposure is nowhere near as important as the actual or estimated amount of chemical in the body and that individual's susceptibility and reaction. The caveat is not to eliminate a chemical exposure from the differential diagnosis because the literature describes "chronic" exposure as pathological and the actual patient suffered an exposure over minutes or hours.

After the above information is obtained, consideration must be given to relating the symptoms and signs to the exposure from a neuropsychiatric standpoint. This assessment is crucial and determines the success of treatment outcome. One should attempt to answer the following questions: are the symptoms a direct result of the toxic exposure?; do the symptoms reflect secondary reaction to other physical or less overt mental impairments from the exposure?; do the symptoms represent anxiety or fear that the individual may have been potentially exposed or could be exposed in the future?; do the symptoms represent an exacerbation or a new manifestation of a concurrent preexisting psychiatric diagnosis?; finally, and most important, is the individual exposed to more than one chemical of neuropsychiatric importance? Unfortunately, as published reports generally do not make these distinctions, the present article cannot do likewise for specific exposures.

\section{Ancillary Examinations}

Occupational chemical exposures commonly cause pulmonary, dermatological, and/or neurological disease. Significant tobacco consumption and illicit drug and alcohol use may be comorbid. Ancillary examinations, depending upon the signs and 
symptoms, might include: multiphasic blood testing of electrolytes, liver function, renal function, and hematologic indices; urinalysis and urine drug screening; serologic tests for syphilis and human immunodeficiency virus; chest Xray; pulmonary function tests; ophthalmological examination; spinal fluid analysis; nerve conduction studies; and skin biopsy.

Tests for measuring specific chemicals of exposure-especially metals-in blood, urine, cerebrospinal fluid, hair, or other tissue specimens should be ordered based upon the occupation and known exposure(s) and as advised by the occupational medicine consultant. Results of qualitative or quantitative "heavy metal screens" of urine or blood-testing for lead, mercury, and arsenic most frequently-can be misleading if used as primary diagnostic indicators without considering other corroborating test results, physical examination findings, and occupational/avocational exposure history. These "screens" can be very expensive, especially when conducted on blood, and results need to be interpreted in light of known test sensitivity and specificity.

\section{Neuropsychological Evaluation}

Neuropsychology evaluation should be considered to support a clinical diagnosis as well as to objectively document findings that could be relevant for workmen's compensation and continuation in the exposure-hazardous work.

Screening tests can be conducted quickly at the bedside or in the office by the psychiatrist (4).

A trained (neuro)psychologist, if available, can conduct testing that has proven useful in the diagnosis of specific exposures (5-7). These include an evaluation of: sensorimotor (fine motor speed and dexterity) skills; visual-motor-spatial ability; abstraction; planning, concentration, cognitive flexibility and efficiency; spatialconstructional praxis; memory; language processes; premorbid abilities ("hold tests"); and personality and mood, e.g., MMPI, Rorschach, depression and anxiety inventories.

\section{DSM-III-R DIAGNOSES ASSOCIATED WITH OCCUPATIONAL EXPOSURES}

This article focuses on those occupational chemical exposures which can be categorized under "Organic Mental Disorders Associated with Axis III Physical Disorders or Conditions, or Whose Etiology is Unknown (2)." Table 1 categorizes specific exposures under DSM-III-R diagnoses. Several clarifications are required in presenting this approach.

The literature in the field of occupational chemical exposures and psychiatric disorders primarily consists of descriptive case studies which are anecdotal and based on relatively few cases. More rigorous epidemiologic studies have been reported among various occupational groups exposed to solvents. A significant limitation, or bias, of this article is the author's assignment of DSM-III and earlier diagnoses as appropriately as possible within present DSM-III-R criteria. Additionally, published 
TABLE 1.

DSM-III-R Organic Mental Disorders and Related Exposures

\begin{tabular}{l}
\hline DELIRIUM \\
Carbon monoxide \\
Lead \\
Arsenic \\
Manganese \\
Solvents \\
Organophosphate pesticides \\
DEMENTIA \\
Solvents \\
Lead \\
Manganese \\
Arsenic \\
ORGANIC DELUSIONAL DISORDER \\
Solvents (toluene) \\
Organophosphate pesticides \\
ORGANIC MOOD DISORDER-MANIC \\
Manganese \\
Tetraethyl lead \\
ORGANIC MOOD DISORDER-DEPRESSION \\
Lead \\
Organophosphate pesticides \\
Carbon monoxide \\
ORGANIC MOOD DISORDER-MIXED \\
Solvents (carbon disulfide) \\
Organic tins (organotins) \\
Inorganic mercury \\
ORGANIC ANXIETY DISORDER \\
Solvent mixtures \\
ORGANIC MENTAL DISORDER NOS \\
Solvents (styrene) \\
Solvent mixtures \\
\hline
\end{tabular}

reports rarely establish a true psychiatric diagnosis and instead list nonspecific signs or symptoms. Again, specific diagnoses were inferred from the given clinical and test information and assigned to appropriate DSM-III-R categories.

The author elected to incorporate many exposures under organic mood disorder. This should not preclude the additional consideration of an organic personality disorder or organic mental disorder NOS, which may be based on extensive longitudinal information in some instances or the inherent variation in clinical assessment among practitioners. Also, some exposures traditionally associated with organic mood disorder or organic anxiety disorder, for example, can present initially with delirium.

Therefore, an important caveat is not to strictly associate a specific exposure with only one or two types of psychiatric disorders. Too little is described in the literature to support such narrow classification. Rather, it is best to consider a 
possible occupational chemical exposure as capable of producing a variety of psychiatric disorders. This will lead to appropriate treatment for the patient's presenting (psychiatric) symptoms and consultation with other medical specialists to determine the feasibility of returning the patient to his previous worksite.

References (3) and (8-11) provide important background information on the exposures discussed here. For brevity, these are not cited with each agent. Relevant literature is cited where indicated. Information on specific doses and durations of treatments is sparsely reported and best obtained through occupational medicine consultation.

\section{DELIRIUM}

Acute lead poisoning can present as an encephalopathy with delirium (12). Exposure occurs through ingestion or inhalation and can be found in a broad spectrum of industries; risk of toxicity varies with the type of industry. Diagnostic laboratory tests include blood lead and zinc protoporphyrin levels and erythrocyte ALA dehydratase assays. Treatment is with chelating agents such as calcium disodium ethylene diaminotetraacetic acid (CaEDTA), British anti-lewisite or BAL (also known as dimercaprol), or penicillamine.

Arsenic enters the body through the respiratory tract primarily and through the gastrointestinal tract. Assays for urinary arsenic and proximal hair shaft levels have been used for diagnostic confirmation. A few case reports have documented arsenic toxicity presenting specifically as a delirium (13-15). Memory impairment persisted after the delirium resolved.

Carbon monoxide poisoning can present with a confusional state and alterations in consciousness. Diagnosis is by carboxyhemoglobin levels and specific history of exposure. The clinical condition is not always correlated with the carboxyhemoglobin level; a patient with a low level may be obtunded, while a patient with a high level may be awake and talking. The classical "cherry red" lips is a variable finding; the diagnosis should not be ruled out by the lack of this physical finding. Treatment is medical and ventilatory support- $100 \%$ oxygen, and hyperbaric oxygen in severe cases.

Organophosphate pesticide poisoning can present acutely as a delirium. These pesticides are absorbed through the skin, lungs, and gastrointestinal tract. As a group, these insecticides inhibit cholinesterase activity and thus lead to classic central and peripheral nervous system (muscarinic and nicotinic) signs and symptoms of increased cholinergic activity. Plasma or serum erythrocyte cholinesterase levels are used diagnostically. Intravenous atropine and 2-pralidoxime chloride are used in treatment.

Manganese exposure can present as a delirium, but the literature describes a more classical manic episode. Thus, manganese is discussed further under the organic mood disorder section. 


\section{DEMENTIA}

Solvents dissolve, extract, or suspend non-water soluble materials. They are grouped into major classes according to chemical structure. These include: hydrocarbons (e.g., pentane, octane, benzene, styrene, toluene, xylene); halogenated compounds (e.g., carbon tetrachloride, trichloroethylene, perchloroethylene); alcohols (e.g., methanol, ethanol); glycols (e.g., ethylene and propylene glycol); ketones (e.g., methyl ethyl ketone); and complex solvents, derived from petroleum. All are volatile, pass through intact skin, have an affinity for nerve tissue because of their lipophilic nature, are soluble in blood, readily pass through lung or gastrointestinal tissue into the blood stream where they can cross the blood-brain barrier.

Water-soluble metabolites of solvents can be measured in the urine, but the relative short half-life of these compounds in the blood dictates that such testing, when available, be performed during the immediate exposure or post-exposure period.

Three chronic syndromes of neurotoxicity secondary to occupational solvent exposure are postulated (16). The first includes CNS symptoms of irritability, memory impairment, and marked fatiguability. The second is a mild toxic encephalopathy with changes in intellect, mood, and/or personality. The third type is a severe toxic encephalopathy, similar to other dementias, and secondary to recurrent heavy exposures. Epidemiologic studies of chronic solvent exposure have primarily been among various industrial painters (cars, houses, ships), varnishers, and carpet layers, who are often exposed to mixtures of solvents. Dementia is especially felt to be a sequelae of chronic solvent exposure among painters (17).

Lead, manganese, and aresenic exposures can lead to memory impairments and decline in social and work functioning suggestive of dementias. These exposures are discussed elsewhere in this section under their more common psychiatric presentations.

\section{ORGANIC DELUSIONAL DISORDER}

Schizophreniform disorder has been anecdotally reported secondary to toluene exposure $(18,19)$.

Two series of case reports described schizophreniform disorder as a consequence of chronic organophosphate pesticide toxicity $(20,21)$.

\section{ORGANIC MOOD DISORDER-MANIC}

Manganese is absorbed through the respiratory and gastrointestinal tracts. Anecdotal case reports, particularly in the first half of this century, described the effects of chronic exposure without personal protective equipment. The first stage is typified as manganese psychosis with mania-“locura manganica" (manganese madness)—with recurrent episodes of significant irritable mood and aggressive 
behavior. A later stage produces symptoms and signs similar to Parkinson's Disease. The use of diagnostic blood or urine manganese levels is controversial. Manganism can be treated with chelation therapy utilizing CaEDTA. L-dopa has also been successfully used, especially in treating the later movement disorders.

Chronic tetraethyl lead exposure, with absorption through the skin and mucous membranes, has caused florid manic episodes with hyperactivity, hallucinations, and delusions that last for days. There is no change in the blood count or increase in heme synthesis metabolites, both of which are observed in inorganic lead poisoning. Treatment is symptomatic; there are no specific antidotes.

\section{ORGANIC MOOD DISORDER-MIXED}

Carbon disulfide toxicity can manifest within a spectrum of mood disorders. These include significant depressive periods as well as a manic irritability bordering on a delirium. Exposure is primarily through the lungs, secondarily through the skin and gastrointestinal tract. Treatment is by removal from the source and supportive measures.

Psychiatric manifestations of organic tin (organotin) exposure have been sporadically documented. In a study of 22 workers with inhalation exposure, episodes of depression interspersed with unprovoked destructive rage, emotional lability, and manic psychosis was observed (22). Urinary tin levels have been used in diagnosis. Treatment is supportive, including reversal of noted cerebral edema.

Inorganic mercury toxicity, as a result of chronic inhalation or ingestion, has been well-documented in descriptive case studies. There is a classic triad of psychiatric changes, gum abnormality, and tremor. Psychiatric signs and symptoms include significant manic-like irritable moods, depressed and anxious moods, social timidity, fatigue and weakness, poor concentration, indecisiveness and helplessness, hygiene neglect, and work deterioration. These personality changes have been called "erethism." The gums demonstrate pigmentary (dark spotting) changes and friability. Fine tremors, seen primarily as resting and intention tremors of the hands with difficulty in writing, are common (23). Measurement of 24 hour urine mercury levels has been used in diagnosis. Treatment is with BAL or penicillamine.

\section{ORGANIC MOOD DISORDER-DEPRESSION}

Significant depressive illness has been documented in workers with chronic low level lead intoxication (24-26).

Chronic exposure to organophosphate pesticides, discussed above, has also been associated with depression (20,21).

Chronic carbon monoxide poisoning can produce depression and apathy. 


\section{ORGANIC ANXIETY DISORDER}

A case-control study of 30 workers and a separate anecdotal report of three workers strongly supports an association between organic solvent toxicity (jet engine fuels, cleaning solutions, paint thinners) and panic disorder $(27,28)$.

A recent study described personality changes in solvent workers that highly resembled personality profiles among persons suffering from post-traumatic stress disorder (5).

\section{ORGANIC MENTAL DISORDER NOT OTHERWISE SPEGIFIED}

Styrene, used in a variety of industries, is toxic through inhalation and can cause a variety of depressive neurasthenic symptoms. Urine mandelic acid is measured as a diagnostic test.

\section{ADDITIONAL UNIQUE REPORTS}

An association between previous occupational solvent exposure and violent crimes was suggested by a retrospective review of the jail records of approximately 14,000 total solvent and non-solvent-exposed workers in Sweden (29). Underlying psychiatric illness was not differentiated.

A recent retrospective cohort mortality study of 1,222 workers found a relationship between phenoxy acid herbicide exposure and suicide (30). These herbicides are used as defoliants, as are dioxin and "Agent Orange," which are byproducts in the manufacturing process. Exposure is primarily through inhalation.

\section{HOBBIES}

Hobbies are an unlikely but definite source of toxic exposure and respiratory/ dermal protection is usually ignored; this should be considered in the patient's history. For example, home auto mechanics may use large quantities of solvents as degreasing agents. Lead exposure can come from stained glass making; fishermen or hunters may be exposed when they melt down scrap metal and mold sinkers or bullets in the home environment. Toluene and other solvent-based glues are readily breathed by persons extensively involved with building scale models.

\section{OCCUPATIONS/AVOCATIONS AND SPECIFIC EXPOSURES}

Table 2 provides a list of occupations, categorized by common chemical exposure. The list is not meant to be exhaustive but to demonstrate the breadth of occupations and avocations related to a single (potentially) toxic exposure $(31,32)$.

\section{MULTIPLE GHEMICAL SENSITIVITIES}

Multiple chemical sensitivities (MCS) is a newly described disorder among workers in industrial as well as office settings. Its features include: 1) being acquired 


\section{Psychiatrically Important Chemical Exposures and Occupations/Avocations at Risk}

Lead

Manganese

Mercury

(inorganic)

Arsenic

Tin

(organotins)

Carbon

disulfide

Styrene

Toluene

Solvents

Organophosphate pesticides

Carbon monoxide
Welders and cutters of lead-painted steel; shipbreaking; primary and secondary lead smelting; paint and varnish manufacturers; lead reclamation from scrap; small foundries; plumbers; ceramic artists; automobile body repair; electric storage battery manufacturers; ammunition industry; automobile radiator manufacturers and soldering; sheet lead workers for storage tanks and reactor vessels; traffic policemen; taxi drivers; garage workers; jewelers;

Manganese miners; manufacturers of paints, varnishes, fireworks, fertilizers, disinfectants; dry cell battery manufacturers; steel alloy plants

Mining and extraction of mercury; feltmaking; taxidermy; photoengraving; scientific personnel; dentists and technicians working with dental amalgams; manufacturers of thermometers, mercury vapor lamps, barometers; chloralkali plant workers; electrical switch manufacturers; embalming; tannery workers; manufacturers and users of pesticides, fungicides, herbicides, and wood preservatives

Manufacturers of insecticides, herbicides, fungicides, silvicides; metallurgy workers; animal husbandry (sheep dipping), pressure treatment of wood

\section{Plastics and rubber industries}

Viscose rayon (especially cellophane) workers; insecticide and fumigant handlers; rubber workers (rubber cement manufacturers, vulcanizing); lacquer and paint manufacturers

Manufacturers of furniture, appliances, and disposable products for the home; automotive components manufacture; plastics workers; fiberglass boat building; rubber industry (numerous products)

Manufacturers of mineral fiber products; photogravure printing work; manufacturers of paints, lacquers, artificial leather, trinitrotoluene (TNT), insect sprays; fabric and paper coating; cleaning and drying agents; histology laboratory technician

Agricultural workers (farmers); anodizers; artists; auto mechanics; automobile body and fender workers; cabinet makers; caulkers; candle makers; carpenters; dental laboratory workers; dry cleaners; electronics workers; electroplaters; electron microscopy technicians; engravers; floor layers; foundry workers; fur processors; glaziers; histology technicians; jewelry repairers/manufacturers; laundry workers; locksmiths; machinists; metal polishers; office workers; optical technicians; painters, paperhangers, and paint manufacturers; papermakers; pest control workers; photographers; plumbers and pipefitters; printers and lithographers; radio and television repairmen; railroad shop workers; roofers; shoe repairers; silk screening workers; tannery workers; tattoo artists; textile workers; theatrical artists; gasoline and aviation fuel manufacturers; solderers; manufacturers of commercial and industrial cleaning agents

Pesticide manufacturers and sprayers; farmers; road construction workers and flagmen

Iron and steel foundry workers; petroleum refinery workers; kraft paper pulp mill workers; formaldehyde and coke manufacturers; welders; garage workers; gasoline-powered forklift operators 
in relation to one or more documented environmental exposure or illness; 2) multiple organs/systems involved; 3) symptoms present, recur, or resolve in response to exposure or withdrawal from the offending environment or chemical; 4) symptoms are caused by exposure to chemicals of unrelated classes; 5) symptoms are caused by exposures that are demonstrable or measurable; 6) symptoms are caused by exposure levels notably below those classically described for specific illness (the latter is the subject of the present article); and 7) there is no single, widely utilized test of physiologic function which can explain or correlate with the symptoms. Reference (33) provides a current and comprehensive overview of the subject, including psychiatric issues and disorders.

\section{REFERENCE SOURCES}

Standard reference texts in neuropsychology or occupational medicine, e.g. $(3,8-9)$, should be available and consulted. Psychiatrists who practice in heavily industrialized regions should consider purchasing these for office use. Plant physicians in large corporate industries should be contacted directly and can provide accurate exposure information on individual patients. However, most industries are relatively small and often have no onsite occupational medicine or industrial hygiene expertise.

Consultations are most likely to be directed at health care personnel specialtytrained within occupational health. Occupational medicine physicians in most instances have completed residencies and board certification in the fields of occupational medicine and/or preventive medicine, may also be specialty-trained in a primary care field, and can provide comprehensive medical care and prevention programs as well as conduct epidemiological investigations. Occupational health nurses provide patient care, conduct occupational surveillance medical examinations and laboratory testing, and administer health maintenance and injury prevention programs. Industrial hygienists quantify specific workplace exposures through onsite visits, advise on needed short-term control measures, and design long-term engineering controls to reduce or eliminate exposures. They complete postgraduate training in this field and attain national certification.

The National Institute for Occupational Safety and Health (NIOSH) is an additional source of information. From 8:00 AM to 4:30 PM Eastern Standard Time, the Cincinnati, Ohio office of NIOSH operates a toll-free telephone number (1-80035NIOSH) for inquiries and information dissemination.

Further information on chemical uses and exposures, as well as toxicity, may be available through NIOSH's National Occupational Exposure Survey and NIOSH's Registry of Toxic Effects of Chemical Substances, through the above telephone number. NIOSH publications can be obtained by calling 1-513-5338287.

If an occupational exposure may have caused or contributed to a patient's psychiatric (or other) illness, it should be remembered from a primary prevention standpoint that NIOSH has the authority to conduct health hazard evaluation (HHE) surveys within most working establishments. A request for a NIOSH HHE 
must come from an authorized representative of the employer or employee. A union representative typically is the authorized employee representative. Alternatively, the signatures of three current employees who are subject to the suspected hazard are legally sufficient to authorize an investigation. The names of the requestors will be kept confidential if requested. The telephone number to call for more information on NIOSH's health hazard evaluation program is 1-513-8414382.

\section{SUMMARY}

Most psychiatrists in practice have little or no experience in occupational medicine. Reference sources are available, some within minutes, for assisting in the evaluation of a psychiatric patient with the possible clinical picture of an occupational chemical intoxication. This chemical exposure-disorder aspect of occupational psychiatry poses numerous challenges for the interested practitioner. The increasing industrialization of the world, with concurrent medicolegal and ethical issues in the workplace, points to an evolving liaison between psychiatry and occupational medicine $(34,35)$.

\section{REFERENCES}

1. Anger WK: Workplace Exposures, In Annau Z (ed): Neurobehavioral Toxicology. Baltimore: Johns Hopkins University Press, 1986

2. American Psychiatric Association: Diagnostic and Statistical Manual of Mental Disorders, Third Edition, Revised. Washington, DC, American Psychiatric Association, 1987

3. Rom WN (ed): Environmental and Occupational Medicine. Boston: Little, Brown, 1983

4. Strub RL, Black FW: The Mental Status Examination in Neurology. 2nd Ed. Philadelphia, F.A. Davis, 1985

5. Morrow LA, Ryan CM, Goldstein G, et al: A distinct pattern of personality disturbance following exposure to mixtures of organic solvents. J Occup Med 31:743-746, 1989

6. White RF, Feldman RG: Neuropsychological assessment of toxic encephalopathy. Am J Ind Med 11:395-398, 1987

7. Hartman DE: Neuropsychological toxicology. Identification and Assessment of Human Neurotoxic Syndromes. New York, Pergamon Press, 1988

8. Zenz C (ed): Occupational Medicine. Principles and Practical Applications. 2nd Ed. Chicago: Year Book, 1988

9. Rosenstock L, Cullen M: Clinical Occpuational Medicine. Philadelphia: W.B. Saunders, 1986

10. Lishman WA: Organic psychiatry. 2nd Ed. Oxford: Blackwell, 1987

11. Vinken PJ, Bruyn GW (eds): Handbook of Clinical Neurology. Volume 36. Intoxications of the Nervous System. Part I. Amsterdam, The Netherlands: North-Holland, 1979

12. Feldman RG: Neurological picture of lead poisoning. Acta Neurol Scandinav 66; suppl 92:185-199, 1982

13. Freeman JW, Couch JR: Prolonged encephalopathy with arsenic poisoning. Neurology 28:853-855, 1978

14. Beckett WS, Moore JL, Keogh JP, et al.: Acute encephalopathy due to occupational exposure to arsenic. Br J Ind Med 43:66-67, 1986 
15. Bolla-Wilson K, Bleecker M: Neuropsychological impairment following inorganic arsenic exposure. J Occup Med 29:499-503, 1987

16. Baker EL, Letz RE, Eisen EA, et al: Neurobehavioral effects of solvents in construction painters. J Occup Med 30:116-123, 1988

17. Gregersen P, Klausen H, Elsnab CU: Chronic toxic encephalopathy in solvent-exposed painters in Denmark 1976-1980: clinical cases and social consequences after a 5-year follow-up. Am J Ind Med 11:399-417, 1987

18. Goldbloom D, Chouinard G: Schizophreniform psychosis associated with chronic industrial toluene exposure: case report. J Clin Psychiatry 46:350-351, 1985

19. Know JW, Nelson JR: Permanent encephalopathy from toluene inhalation. New Eng J Med 275:1494-1496, 1966

20. Gershon S, Shaw FH: Psychiatric sequelae of chronic exposure to organophosphorus insecticides. Lancet i:1371-1374, 1961

21. Dille JR, Smith PW: Central nervous system effects of chronic exposure to organophosphate insecticides. Aerospace Med 35:475-478, 1964

22. Ross WD, Emmett EA, Steiner J, et al: Neurotoxic effects of occupational exposure to organotins. Am J Psychiatry 138:1092-1095, 1981

23. Ross WD, Gechman AS, Sholiton MC, et al: Need for alertness to neuropsychiatric manifestations of inorganic mercury poisoning. Compr Psychiatry 18:595-598, 1977

24. Schottenfeld RS, Cullen MR: Organic affective illness associated with lead intoxication. Am J Psychiatry 141:1423-1426, 1984

25. Cullen MR, Robins JM, Eskenazi B: Adult inorganic lead intoxication-presentation of 31 new cases and a review of recent advances in the literature. Medicine (Baltimore) 247:221-247, 1983

26. Baker EL, Feldman RG, White RF, et al: The role of occupational lead exposure in the genesis of psychiatric and behavioral disturbances. Acta Psychiat Scand 67; suppl 303:3848,1983

27. Dager SR, Holland JP, Cowley DS, et al: Panic disorder precipitated by exposure to organic solvents in the work place. Am J Psychiatry 144:1056-1058, 1987

28. Struwe G, Knave B, Mindus P: Neuropsychiatric symptoms in workers occupationally exposed to jet fuel-a combined epidemiological and casuistic study. Acta Psychiat Scand 67: suppl 363:55-67, 1983

29. Lidberg L, Tael T, Wiklund N: Violent crime and occupational exposure to organic solvents. Lancet ii: 1080, 1987

30. Green L: Suicide and exposure to phenoxy acid herbicides. Scand J Work Environ Health $13: 460,1987$

31. Key MM, Henschel AF, Butler J, et al. (eds): Occupational Diseases. A guide to their recognition. Washington, DC: National Institute for Occupational Safety and Health, 1977

32. Adams R, Occupational Skin Diseases. New York: Grune \& Stratton, 1983

33. Cullen ME (ed): Workers with Multiple Chemical Sensitivities. Occupational Medicine: State of the Art Reviews 2(4):655-804, 1987

34. O'Flynn RR: Psychiatric research in occupational medicine: the future of an illusion. $\mathrm{Br} \mathrm{J}$ Ind Med 45:1-4, 1988

35. Landrigan PJ: Toxic exposures and psychiatric disease-lessons from the epidemiology of cancer. Acta Psychiat Scand 67:Suppl 303:6-15, 1983 